\title{
IAP Commitment to Nurturing Care for Early Childhood Development
}

\author{
PiYush GuPTA \\ National President Indian Academy of Pediatrics, 2021 \\ president@iapindia.org
}

$\mathrm{D}$ evelopment is traditionally defined as a qualitative phenomenon that encompasses a "progressive series of orderly coherent changes" that occur as a result of maturity and experience. It may also be defined as behavioral changes in skills and functional abilities. Child development refers to "gaining of skills in all aspects of a child's life like physical development, social and emotional development, intellectual development, communication and speech development" [1]. Traditionally it is taught that "development" is fundamentally different from "growth" that refers to increase in physical size, attained by increase in body mass including that of fat, muscle, tissues, and bone. However, it is now being increasingly recognized that these terms are inseparable, and cannot be seen in isolation from each other. This is also evident from the fact that factors that affect growth and development can not be differentiated. Poverty, broken homes, nutritional insults, and parental education, affect both. An imbalance between protective and risk factors affect brain growth, physical health and psychological development. In 2017, Lancet reported that 250 million children (43\%) in middle-income countries do not reach their optimal development potential. The India country profile in the 'Countdown to 2030 Women's, Children's, and Adolescent's Health' estimates that $45 \%$ children under 5 years are at risk, amounting to 70 million by the current census [2].

Early childhood development (ECD) represents one of the foci of the 'Survive, Thrive, Transform' agenda of the Global Strategy for Women, Children and Adolescent Health (2016-2030). ECD is a generic term that refers to a child's cognitive, social, emotional, language and physical development. Early childhood starts from the time of conception and may span up to first 8 years of life. Realizing that the ultimate functional potential of humans is primarily dependent on brain growth that occurs in the first two to three years of life, the emphasis has shifted to protect, promote and support growth and development in this critical period. From this broad age range, the current focus is on the nurturing care of children in their formative years i.e. between $0-5$ years, to achieve optimal development [3]. The domains of nurturing care for early child-hood development (NC-ECD) include: i) Good health; ii) Adequate nutrition; iii) Safety and security; iv) Responsive parenting; and v) Facilitating opportunities for early learning. Taking cognizance of the importance of ECD, Indian Academy of Pediatrics (IAP) has partnered with the World Health Organization (WHO) and United Nations Children's Fund (UNICEF), on multiple fronts that includes advocacy, submitting recommendations to policy makers, and sensitization of pediatricians regarding the importance of NC-ECD. This supplement is another effort from the IAP, ably supported by the WHO. The supplement will go to over 30,000 members of the academy and create awareness on the current status of national preparedness for implementing NC-ECD in India. Consider it a prelude to the nationwide campaign and training of more than 8,000 pediatricians in the next two years. I am sure this will serve as the foundation stone for the mansion that IAP is looking forward to build, which will house the incorporation of NC$\mathrm{ECD}$ in office practice of all its members in the coming years.

\section{REFERENCES}

1. Gupta P, Kaushik JS, Dubey R, Dabas A. Growth and Development. Textbook of Pediatrics. 2nd ed. CBS Publishers and Distributors Pvt Ltd; 2019. p. 1-49.

2. Countdown to 2030. Women, Children and Adolescents Health. India Country Profile. Accessed January 18, 2021. Available from: www. nurturing-care.org

3. World Health Organization. Operationalizing Nurturing Care for Early Childhood Development. Geneva; WHO; 2019. 